\title{
Orthography shapes the perception of speech: The consistency effect in auditory word recognition
}

\author{
JOHANNES C. ZIEGLER \\ Macquarie University, Sydney, New South Wales, Australia \\ and CNRS, Aix-en-Provence, France \\ and \\ LUDOVIC FERRAND \\ CNRS and Université René Descartes, Paris, France
}

\begin{abstract}
Inconsistency in the spelling-to-sound mapping hurts visual word perception and reading aloud (i.e., the traditional consistency effect). In the present experiment, we found a consistency effect in auditory word perception: Words with phonological rimes that could be spelled in multiple ways produced longer auditory lexical decision latencies and more errors than did words with rimes that could be spelled only one way. This finding adds strong support to the claim that orthography affects the perception of spoken words. This effect was predicted by a model that assumes a coupling between orthography and phonology that is functional in both visual and auditory word perception.
\end{abstract}

The traditional consistency/regularity effect consists of the finding that inconsistency in the spelling-to-sound mapping hurts word perception and reading aloud. Such inconsistency arises when a subword spelling can be pronounced in multiple ways (e.g., -ough can be pronounced as in cough, dough, through, bough, tough; see Ziegler, Stone, \& Jacobs, 1997). The consistency/regularity effect in normal and impaired reading has been a major constraint for the development of theories and recent computational models of reading (e.g., Coltheart, 1978; Coltheart, Curtis, Atkins, \& Haller, 1993; Glushko, 1979; Plaut, McClelland, Seidenberg, \& Patterson, 1996; Seidenberg \& McClelland, 1989; Van Orden \& Goldinger, 1994; Van Orden, Pennington, \& Stone, 1990).

The consistency effect has played a major role in reading research because it shows not only that words are perceived and read aloud by one's accessing their form as a whole in the mental lexicon (addressed phonology), but that grain sizes smaller than the whole word (subword patterns) are functional in reading (assembled phonology). In addition, the very existence of consistency effects in word perception tasks rules out purely visual or orthographic word recognition models, because the consis-

This research was supported by grants from the Fondation Fyssen and the Australian Research Council. We are grateful to Madeleine Leveillé, Denis Lancelin, and Fanny Meunier for their help in setting up the experiment. Thanks are extended to Max Coltheart, Ram Frost, Randi Martin, Kathy Rastle, Mich Sommers, and an anonymous reviewer for helpful feedback on an earlier version of this manuscript. Correspondence concerning this article should be addressed to J. C. Ziegler, School of Behavioural Sciences, Macquarie University, Sydney, NSW 2109, Australia (e-mail: jziegler@frogmouth.bhs.mq.edu.au). tency manipulation (i.e., multiple pronunciations for one spelling) is de facto a phonological manipulation.

Until recently, researchers investigating visual word recognition have considered only inconsistency between orthography and phonology (i.e., multiple ways to pronounce a spelling), not inconsistency between phonology and orthography (i.e., multiple ways to spell a pronunciation). The reason why researchers have studied spellingto-sound inconsistency exclusively may be due to the fact that in most of the visual word recognition models, activation flows only from orthography to phonology, not from phonology to orthography. According to such one-way models, then, spelling-to-sound inconsistency matters, whereas sound-to-spelling inconsistency is irrelevant.

In contrast, a recurrent feedback model assumes a bidirectional flow of activation between orthography and phonology (e.g., Stone, Vanhoy, \& Van Orden, 1997; Stone \& Van Orden, 1994; Van Orden \& Goldinger, 1994; Van Orden, Jansen op de Haar, \& Bosman, 1997). In such a model, the visual presentation of a word activates letter nodes, which, in turn, activate phoneme nodes. Similarly, the presentation of a spoken word activates phoneme nodes, which, in turn, activate letter nodes. Following initial activation, recurrent feedback begins between these two node families. Whenever the activation that is "sent" is compatible (i.e., consistent) with the activation that is "returned," nodes conserve and strengthen their activation in relatively exclusive and stable feedback loops. The capacity to conserve and strengthen activation thus depends on the consistency of the coupling between orthography and phonology (for one possible implementation of such a model, see Jacobs, Rey, Ziegler, \& Grainger, 1998). Such a model naturally predicts that not only 
spelling-to-sound inconsistency (feedforward inconsistency) but also sound-to-spelling inconsistency (feedback inconsistency) affects the perception of words.

This somewhat counterintuitive prediction has recently been corroborated in a visual lexical decision task in English and French (Stone et al., 1997; Ziegler, Montant, \& Jacobs, 1997). These authors found that words with phonological rimes that could be spelled more than one way (e.g., /-ip/ may be spelled -eap or -eep) produced slower correct "yes" responses and more errors than did words with phonological rimes that could be spelled only one way (e.g., /-uk / may only be spelled -uck). This finding has been called the feedback consistency effect. Further evidence for the claim that a bidirectional coupling between orthography and phonology may underlie word perception comes from a naming experiment (Ziegler, Montant, \& Jacobs, 1997) and several letter search experiments (Ziegler \& Jacobs, 1995; Ziegler, Van Orden, \& Jacobs, 1997). In both sets of experiments, performance was affected when stimulus phonology could be spelled in multiple ways.

The recurrent network approach described above assumes that the coupling between orthography and phonology constitutes a general mechanism not only in visual word perception but also in auditory word perception. According to this approach, the major difference between auditory and visual word perception is that activation begins in the phoneme nodes in auditory word recognition, whereas it begins in the letter nodes in visual word recognition. However, the dynamics between orthography and phonology that follow this initial activation are assumed to be similar. Therefore, we predict that sound-to-spelling inconsistency should affect auditory word perception much in the same way as it affects visual word perception. In the present experiment, we sought to detect such an auditory consistency effect.

Surprisingly, there seem to have been no studies in the literature in which researchers have looked explicitly for an auditory equivalent of the consistency effect obtained in visual word perception. Perhaps consistency effects have been ignored in studies of speech perception because models in this domain typically assume that spoken words are perceived without reference to their orthography (e.g., Marslen-Wilson, 1987; McClelland \& Elman, 1986; Norris, 1994). However, orthography effects in spoken word recognition have been found in a few studies, using the rhyme-judgment task (Donnenwerth-Nolan, Tanenhaus, \& Seidenberg, 1981; Seidenberg \& Tanenhaus, 1979), the print-sound matching task (R. Frost, Repp, \& Katz, 1988), the primed auditory lexical decision task (Jakimik, Cole, \& Rudnicky, 1985), and the phoneme monitoring task (Dijkstra, Roelofs, \& Fieuws, 1995; Frauenfelder, Segui, \& Dijkstra, 1990). For example, in a rhyme-judgment task, using auditorily presented words, Seidenberg and colleagues found that rime decisions were faster when cue-target pairs were orthographically similar (e.g., pielie) than when they were orthographically dissimilar (e.g., rye-lie), even when cues were presented auditorily. These studies suggest that orthographic information seems to be activated during auditory word recognition, at least to some extent.

However, the studies mentioned above relied on the fact that the target's competing spelling or pronunciation was introduced in the form of a prime (Jakimik et al., 1985), a cue (R. Frost et al., 1988; Seidenberg \& Tanenhaus, 1979), or a target phoneme (Dijkstra et al., 1995). Instead, the classic consistency manipulation does not require the competing spelling or pronunciation to be presented before or at the same time as the target word, nor does the target word need to be matched to its competitor in any obvious way. For this reason, it seems that finding a consistency effect in auditory lexical decision may be the strongest demonstration for a coupling between orthography and phonology that is functional in both visual and auditory word perception.

To summarize, the present experiment was aimed at finding a consistency effect in auditory word perception. By analogy with recent visual word perception experiments (Stone et al., 1997; Ziegler, Montant, \& Jacobs, 1997), we predicted that lexical decision performance to auditorily presented words would be worse if their rimes could be spelled in multiple ways (i.e., feedback inconsistent) than if their rimes could be spelled only one way (i.e., feedback consistent).

\section{METHOD}

\section{Participants}

Eighty-two psychology students from the École des Psychologues Praticiens in Paris participated in the study: 22 in the auditory lexical decision task and 60 in the familiarity rating. All were French native speakers. None of the 22 participants in the auditory experiment had any hearing problems.

\section{Stimuli and Design}

The stimulus set consisted of 70 monosyllabic words and 70 monosyllabic nonwords. Of the words, 35 were consistent and 35 were inconsistent. Consistent words contained phonological rimes that could be spelled in only one way. In contrast, inconsistent words contained rimes that could be spelled in more than one way (see Table 1). For example, the phonological rime of the consistent French word stage can only be spelled -age as in stage, rage, cage, etc. In contrast, the phonological rime of the inconsistent French word plomb can be spelled in different ways, as in nom, prompt, ton, tronc, long, etc. All items are listed in the Appendix.

Stimulus selection was done on the basis of a statistical analysis of bidirectional consistency of spelling and sound in French (Ziegler, Jacobs, \& Stone, 1996). This database lists the phonological rimes of all monosyllabic words with their corresponding spelling and consistency ratio. The consistency ratio, also referred to as conditional probability, varies between 0 and $l$ and reflects the degree of (in)consistency. The consistency ratio is the summed frequency of a word's friends relative to the summed frequency of a word's friends plus enemies. ' A consistency ratio greater than .5 indicates that a word has more or stronger friends than enemies. A consistency ratio smaller than .5 indicates that a word has less or weaker enemies than friends. As can be seen in Table 1, the consistency ratio of our inconsistent words was very low (i.e., they had strong enemies). We deliberately chose words with strong enemies because previous consistency research in visual word recognition had suggested that the size of the consistency effect is most strongly 
Table 1

Stimulus Characteristics of Words Used in Experiment 1

\begin{tabular}{lcc}
\hline \multicolumn{1}{c}{ Variable } & Consistent & Inconsistent \\
\hline No. rime spellings & 1.00 & 6.02 \\
Consistency ratio & 1.00 & 0.05 \\
Frequency (per million) & 6.91 & 6.97 \\
Familiarity (7-point scale) & 4.49 & 4.23 \\
No. phonological neighbors & 7.50 & 8.60 \\
Uniqueness point & 4.14 & 4.14 \\
No. phonemes & 3.40 & 3.23 \\
Mean duration (msec) & 559 & 531 \\
\hline
\end{tabular}

determined by the frequency of a word's enemies (e.g., Jared, McRae, \& Seidenberg, 1990). The consistency ratio for auditorily presented nonwords cannot be given, because one simply does not know the "correct" spelling of an inconsistent nonword. For example, the nonword /301/ could be spelled jaur, jaure, jor, jorc, jord, jore, jorps, jors, or jort. To maximize enemy frequency for nonwords, we used rimes with multiple spellings but no dominant spelling.

As can be seen in Table 1, consistent and inconsistent words were matched for a number of variables: word frequency, familiarity (see below), number of phonological neighbors, uniqueness point, and number of phonemes. Word frequencies were estimated according to a French frequency count described in Content, Mousty, and Radeau (1990). The number of phonological neighbors gives the number of words that can be obtained by changing one phoneme. The uniqueness point is the point from word onset at which only one candidate remains in the cohort of possible words (see Content et al., 1990). Statistical tests revealed that the consistent and inconsistent words did not differ significantly on any of these potentially confounding variables [frequency, $t(68)=.02$; familiarity, $t(68)=.98$; number of neighbors, $t(68)=.82$; uniqueness point, $t(68)=0$; number of phonemes, $t(68)=1.19]$.

Following Goldinger's (1996) recommendation, the durations of the words and nonwords were measured for each condition. In the word condition, the mean word length was $559 \mathrm{msec}$ (range: $380-780$ ) for consistent words and $531 \mathrm{msec}$ (range: $320-750$ ) for inconsistent words. In the nonword condition, the mean length was $595 \mathrm{msec}$ (range: 430-850) for consistent nonwords and 511 msec (range: $330-700$ ) for inconsistent nonwords. Because of these differences in duration, we treated duration as a covariate in the item analyses reported below.

\section{Familiarity Ratings}

Because there may be wide differences in subjective familiarity for stimuli matched in word frequency (Gernsbacher, 1984), we obtained familiarity ratings for our word stimuli. For this purpose, 60 participants received a booklet that contained our stimuli in randomized order for each participant. On the top of each sheet was a graphic illustration of the 7-point scale, with a verbal label for each point (e.g., $1=$ extremely unfamiliar, $7=$ extremely familiar). Next to each item, the 7 numbers were repeated with a verbal label for the two anchor points. Participants were asked to circle the number that corresponded best to the familiarity of the item. Mean familiarity for the two groups of items is given in Table 1; mean familiarity scores for each item are listed in the Appendix.

\section{Procedure}

Practice and experimental items were recorded by a male French native speaker in a soundproof room on a digital audiotape recorder (Teac DA-P20) with a Sennheiser MD43 microphone. Items were digitized at a sampling rate of $48 \mathrm{kHz}$ with 16-bit analog-to-digital conversion using a Macintosh IIfx computer and an audiomedia editor. The stimuli were transferred to the left channel of the Teac DA-P20 digital-to-analog converter. A $1000-\mathrm{kHz}$ pulse on the right channel (inaudible to participants) was time-locked with the onset of the stimulus. This signal started the timer, which was stopped by participants' lexical decision responses. The intertrial interval was $2 \mathrm{sec}$

Stimulus presentation and data collection were controlled by an $386 \mathrm{PC}$ connected to the digital-to-analog converter. The stimuli were presented to the participants at a comfortable level through a pair of Sony MDR-PI headphones connected to the left channel of the digital-to-analog converter. Participants were tested individually in a sound-proof room. Participants were instructed to decide as quickly as possible whether the auditorily presented stimulus was a real French word (standard auditory lexical decision task). Participants gave their responses by pressing either the "yes" or the "no" button of a button box that was placed in front of them. The dominant hand was used for the "yes" responses. At the beginning of the experiment, participants were given 20 practice trials to become familiarized with the task. During the experiment, no feedback was provided. The experiment lasted for approximately $15 \mathrm{~min}$.

\section{RESULTS}

Mean reaction times (RTs) and error rates for consistent and inconsistent words and nonwords are presented in Table 2. Item means are given in the Appendix. RTs were measured from target onset to response onset. RTs longer than $1,500 \mathrm{msec}$ or shorter than $150 \mathrm{msec}$ were discarded from the analyses (less than $1 \%$ of the data). Planned comparisons were performed on correct mean RTs and error rates with both subjects $\left(t_{1}\right)$ and items $\left(t_{2}\right)$ as the random variable.

The data clearly showed a strong consistency effect for words. Participants took longer $(62 \mathrm{msec})$ and made more errors (13.1\%) on lexical decisions to inconsistent words as opposed to consistent words. This consistency effect for words was significant by subjects and by items [RTs, $t_{1}(21)=10.81, p<.001 ; t_{2}(68)=3.13, p<.005$; errors, $\left.t_{1}(21)=6.8, p<.001 ; t_{2}(68)=1.87, p<.05\right]$. With respect to nonwords, there was no significant consistency effect for nonwords (RTs, $t_{1}(21)=1.27$, and $t_{2}(68)<1$; errors, all $t \mathrm{~s}<1)$.

Because of differences in auditory presentation duration between consistent and inconsistent words and nonwords, we computed covariance analyses on the item data with consistency as the independent variable and duration as the covariate. These analyses confirmed that, when word duration was taken into account, the consistency effect for words was still highly significant $[F(1,67)=8.55, p<$ $.005]$. The covariate duration was marginally significant $[F(1,67)=3.64, p<.06]$. As concerns nonwords, the covariance analysis confirmed the absence of a significant consistency effect for nonwords $[F(1,67)=.16, p<.7]$. The covariate duration was not significant $[F(1,67)=1.57$, $p<.21]$. On the basis of this analysis, it seems unlikely that differences in mean duration between consistent and inconsistent nonwords have masked a potential consistency effect for nonwords.

Table 2

Mean Reaction Times (RTs) and Standard Errors (SE)

for Correct Responses and Percentage of Errors $(\% \mathrm{E})$ for Consistent and Inconsistent Words and Nonwords (Auditory Lexical Decision Task)

\begin{tabular}{|c|c|c|c|c|c|c|c|c|}
\hline & \multicolumn{4}{|c|}{ Consistent } & \multicolumn{4}{|c|}{ Inconsistent } \\
\hline & \multicolumn{2}{|c|}{ RT } & \multicolumn{2}{|c|}{$\% \mathrm{E}$} & \multicolumn{2}{|c|}{ RT } & \multicolumn{2}{|c|}{$\% \mathrm{E}$} \\
\hline & $M$ & $S E$ & $M$ & $S E$ & $M$ & $S E$ & $M$ & $S E$ \\
\hline wo & 756 & 10.7 & 7.8 & 0.9 & 818 & 11.4 & 20.9 & 2.1 \\
\hline Nonwords & 859 & 14.3 & 11.0 & 2.0 & 864 & 15.1 & 13.1 & 2.8 \\
\hline
\end{tabular}




\section{DISCUSSION}

In the present experiment, we found a consistency effect in auditory word perception. Words with phonological rimes that could be spelled in multiple ways produced longer auditory lexical decision latencies and more errors than did words with rimes that could be spelled only one way. Because in a recent study similar auditory consistency effects were found for English (S. J. Frost, Fowler, \& Rueckl, 1998), it seems unlikely that the present effect was due to particularities of French. The existence of a consistency effect in auditory word recognition adds strong support to the claim that orthographic information affects the perception of spoken words (Dijkstra et al., 1995; Donnenwerth-Nolan et al., 1981; Jakimik et al., 1985, Seidenberg \& Tanenhaus, 1979).

The existence of a consistency effect is based on comparisons between different words. Therefore, one has to ensure that the different groups of stimuli do not systematically differ on a dimension other than consistency. Because recent studies had suggested that low-frequency inconsistent words were rated as less familiar than low-frequency consistent words even though they were perfectly matched on objective frequency (S. J. Frost et al., 1998; Peereman, Content, \& Bonin, 1998), we had participants rate our stimuli for familiarity. The results showed that our consistent and inconsistent words did not significantly differ in rated familiarity. Although we believe that familiarity ratings might, at least to some extent, reflect spelling-to-sound inconsistency (i.e., inconsistent words tend to look and/or sound less familiar than consistent words), the present consistency effect is not reducible to simple differences in rated familiarity.

The presence of a feedback consistency effect in both visual and auditory word recognition was predicted by a model which assumed a bidirectional flow of activation, a coupling between orthography and phonology at various grain sizes (e.g., R. Frost \& Katz, 1989; Stone et al., 1997; Van Orden \& Goldinger, 1994; Van Orden et al., 1997). Although the present study did not contain a frequency manipulation, we suspect that the auditory consistency effect, much like the visual consistency effect, is stronger for low-frequency words than for high-frequency words (see, e.g., Seidenberg, Waters, Barnes, \& Tanenhaus, 1984). A resonance model may account for the consistency $\times$ frequency interaction, because it assumes that the greater amount of learning for high-frequency words will reinforce spelling-to-sound mappings at the biggest grain size (i.e., word level). Except with homographs and homophones, inconsistency at this level is smaller than inconsistency at the subword level. Thus, the more stable word-level grain sizes of highfrequency words can help the inconsistent words to overcome competition at subword grain sizes more efficiently.

As concerns the nonword data ("no" responses), we did not find a consistency effect for nonwords. This comes as no surprise, because both Stone et al. (1997) and Ziegler, Montant, and Jacobs (1997) failed to find consistency effects for nonwords in the visual lexical decision task. At first glance, the absence of a consistency effect for nonwords seems to be incompatible with our claim that consistency effects should be stronger for low-frequency words than for high-frequency words. One may argue that nonwords should pattern more like low- than like high-frequency words and thus exhibit even stronger consistency effects. Although this may be true for naming, it is certainly not the case for lexical decision. All major models of the lexical decision task agree that words and nonwords are classified on the basis of distinct mechanisms (e.g., Coltheart, Davelaar, Jonasson, \& Besner, 1977; Grainger \& Jacobs, 1996). Words are accepted when some sort of local activation in an individual word unit has passed a critical activation threshold. For example, low-frequency words will take longer to pass this critical activation threshold than will high-frequency words. The rise of activation in these word units will be slowed down even further by competition from inconsistent neighbors. Nonwords, however, are rejected by a different mechanism; they are "timed out" when no single word unit has passed the activation threshold before a certain time threshold. Because inconsistency affects the rise of activation but not the position of the time threshold, we did not expect consistency effects for nonwords in the lexical decision task. Our recent simulation work has conf irmed that such response mechanisms and processing dynamics predict feedback consistency effects for words and their absence for nonwords (see Jacobs et al., 1998).
The existence of an auditory consistency effect questions the assumption that speech processing is completely independent of written language. Of course, when children first learn to produce and understand speech, speech processing is necessarily independent of the not yet acquired written language. However, as children learn to read and to write, associations between written and spoken language are established. As a consequence, sound representations seem to become more and more sensitive to written language (Ehri, 1984). For example, Treiman and Cassar (1997) showed that sound judgments of children in the first grade are already affected by simple orthographic knowledge (i.e., knowledge about letter names). They concluded that once children have started reading instruction, they are no longer able to completely separate sound and spelling. In addition, the influence of orthographic knowledge on speech processing seems to become stronger as children become fluent readers and writers (Zecker, 1991). Thus, if the auditory consistency effect is the result of an increasing influence of orthography on speech processing as children learn to read and write, this effect should be weaker in children and absent in illiterate adults.

In summary, in much of our previous research, we have mainly investigated one part of the coupling between orthography and phonology, showing that phonology affects the perception of print (Ferrand \& Grainger, 1992, 1993, 1996; Grainger \& Ferrand, 1994, 1996; Ziegler \& Jacobs, 1995; Ziegler, Van Orden, \& Jacobs, 1997). In the present research, we have extended this work by showing that orthography also affects the perception of speech. The underlying mechanism can be seen as a coupling between orthography and phonology that is functional in both visual and auditory word perception.

\section{REFERENCES}

Coltheart, M. (1978). Lexical access in simple reading tasks. In G. Underwood (Ed.), Strategies of information processing (pp. 151 216). London: Academic Press.

Coltheart, M., Curtis, B., Atkins, P., \& Haller, M. (1993). Models of reading aloud: Dual-route and parallel-distributed-processing approaches. Psychological Review, 100, 589-608.

Coltheart, M., Davelaar, E., Jonasson, J. T., \& Besner, D. (1977). Access to the internal lexicon. In S. Dornic (Ed.), Attention and performance VI (pp. 535-555). Hillsdale, NJ: Erlbaum.

Content, A., Mousty, P., \& Radeau, M. (1990). BRULEX: Une base de données lexicales informatisée pour le Français écrit et parlé. Année Psychologique, 90, 551-566.

Dijkstra, T, Roelofs, A., \& Fieuws, S. (1995). Orthographic effects on phoneme monitoring. Canadian Journal of Experimental Psychology, 49, 264-271.

Donnenwerth-Nolan, S., Tanenhaus, M. K., \& Seidenberg, M. S. (1981). Multiple code activation in word recognition: Evidence from rhyme monitoring. Journal of Experimental Psychology: Human Learning \& Memory, 7, 170-180.

EHRI, L. C. (1984). How orthography alters spoken language competencies in children learning to read and spell. In J. Downing \& R. Valtin (Eds.), Language awareness and learning to read (pp. 119-147). New York: Springer-Verlag.

Ferrand, L., \& Grainger, J. (1992). Phonology and orthography in visual word recognition: Evidence from masked nonword priming. Quarterly Journal of Experimental Psychology, 42A, 353-372.

FERRAND, L., \& GRAINGER, J. (1993). The time course of orthographic and phonological code activation in the early phases of visual word recognition. Bulletin of the Psychonomic Society, 31, 119-122.

Ferrand, L., \& Grainger, J. (1996). List context effects on masked phonological priming in the lexical decision task. Psychonomic Bulletin \& Review, 3, 515-519.

Frauenfelder, U. H., Segui, J., \& Dijkstra, T. (1990). Lexical effects in phonemic processing: Facilitatory or inhibitory? Journal of Experimental Psychology: Human Perception \& Performance, 16, 77-91.

Frost, R., \& KaTZ, L. (1989). Orthographic depth and the interaction of visual and auditory processing in word recognition. Memory \& Language, 17, 302-310.

Frost, R., RePP, B. H., \& KatZ, L. (1988). Can speech perception be influenced by simultaneous presentation of print? Journal of Memory \& Language, 27, 741-755. 
Frost, S. J., Fow Ler, C. A., \& RueckL, J. G. (1998). Bidirectional consistency: Effects of phonology common to speech and reading. Manuscript submitted for publication.

GerNSBACHER, M. A. (1984). Resolving 20 years of inconsistent interactions between lexical familiarity and orthography, concreteness, and polysemy. Journal of Experimental Psychology: General, 113, 256-281.

GlushKo, R. J. (1979). The organization and activation of orthographic knowledge in reading aloud. Journal of Experimental Psychology. Human Perception \& Performance, 5, 674-691.

Goldinger, S. D. (1996). Auditory lexical decision. Language \& Cognitive Processes, 11, 559-567.

Grainger, J., \& Ferrand, L. (1994). Phonology and orthography in visual word recognition: Effects of masked homophone primes. Journal of Memory \& Language, 33, 218-233.

Grainger, J., \& FerRand, L. (1996). Masked orthographic and phonological priming in visual word recognition and naming: Cross-task comparisons. Journal of Memory \& Language, 35, 623-647.

GraingER, J., \& JACOBS, A. M. (1996). Orthographic processing in visual word recognition: A multiple read-out model. Psychological Review, 103, 518-565.

Jacobs, A. M., Rey, A., Ziegler, J. C., \& Grainger, J. (1998). MROM-P: An interactive activation, multiple read-out model of orthographic and phonological processes in visual word recognition. In J. Grainger \& A. M. Jacobs (Eds.) Localist connectionist approaches to human cognition (pp. 147-188). Mahwah, NJ: Erlbaum

J AKIMIK, J., COLE, R. A., \& RUDNICKY, A. I. (1985). Sound and spelling in spoken word recognition. Journal of Memory \& Language, 24, 165-178.

JaRed, D., McRae, K., \& SeidenberG, M. S. (1990). The basis of consistency effects in word naming. Journal of Memory \& Language, 29, 687-715.

MARSLEN-Wilson, W. D. (1987). Functional parallelism in spoken word recognition. Cognition, 25, 71-102.

McClelland, J. L., \& Elman, J. L. (1986). The TRACE model of speech perception. Cognitive Psychology, 18, 1-86.

NoRRIS, D. (1994). SHORTLIST: A connectionist model of continuous speech recognition. Cognition, 52, 189-234.

Peereman, R., Content, A., \& Bonin, P. (1998). Is perception a twoway street? The case of feedback consistency in visual word recognition. Journal of Memory and Language, 39, 151-174.

Plaut, D. C., McClelland, J. L., SeidenberG, M. S., \& Patterson, K. (1996). Understanding normal and impaired word reading: Computational principles in quasi-regular domains. Psychological Review, 103, 56- 115.

SeidenberG, M. S., \& McClelland, J. L. (1989). A distributed developmental model of word recognition and naming. Psychological Review, 96, 523-568

Seidenberg, M. S., \& Tanenhaus, M. K. (1979). Orthographic effects on rhyme monitoring. Joumal of Experimental Psychology: Human Learning \& Memory, 5, 546-554.
Seidenberg, M. S., Waters, G. S., Barnes, M. A., \& Tanenhaus, M. K. (1984). When does irregular spelling or pronunciation influence word recognition? Journal of Verbal Learning \& Verbal Behavior, 23, 383-404.

Stone, G. O., Vanhoy, M. D., \& Van Orden, G. C. (1997). Perception is a two-way street: Feedforward and feedback phonology in visual word recognition. Journal of Memory \& Language, 36, 337-359.

Stone, G. O., \& VAN Orden, G. C. (1994). Building a resonance framework for word recognition using design and system principles. Journal of Experimental Psychology: Human Perception \& Performance, 20, 1248-1268

Treiman, R., \& Cassar, M. (1997). Can children and adults focus on sound as opposed to spelling in a phoneme counting task? Developmental Psychology, 33, 771-780.

VAN ORDEN, G. C., \& GoldingER, S. D. (1994). Interdependence of form and function in cognitive systems explains perception of printed words. Journal of Experimental Psychology: Human Perception \& Performance, 20, 1269-1291.

Van Orden, G. C., Jansen op de HaAR, M. A., \& Bosman, A. M. T. (1997). Complex dynamic systems also predict dissociations, but they do not reduce to autonomous components. Cognitive Neuropsychology, 14, 131-165.

Van Orden, G. C., Pennington, B. F., \& Stone, G. O. (1990). Word identification in reading and the promise of subsymbolic psycholinguistics. Psychological Review, 97, 488-522.

ZECKER, S. G. (1991). The orthographic code: Developmental trends in reading-disabled and normally-achieving children. Annals of Dyslexia, 41, 178-192.

Ziegler, J. C., \& JaCoBs, A. M. (1995). Phonological information provides early sources of constraint in the processing of letter strings. Journal of Memory \& Language, 34, 567-593.

Ziegler, J. C., JACOBS, A. M., \& STONE, G. O. (1996). Statistical analysis of the bidirectional inconsistency of spelling and sound in French. Behavior Research Methods, Instruments, \& Computers, 28, 504-515.

Ziegler, J. C., Montant, M., \& JaCoBs, A. M. (1997). The feedback consistency effect in lexical decision and naming. Journal of Memory \& Language, 37, 533-554.

Ziegler, J. C., Stone, G. O., \& JACoBS, A. M. (1997). What's the pronunciation for -ough and the spelling for / $/$ /? A database for computing feedforward and feedback consistency in English. Behavior Research Methods, Instruments, \& Computers, 29, 600-618.

Ziegler, J. C., Van Orden, G. C., \& Jacobs, A. M. (1997). Phonology can help or hurt the perception of print. Journal of Experimental Psychology: Human Perception \& Performance, 23, 845-860.

\section{NOTE}

1. Enemies in visual word recognition are defined as words with the same orthographic rime (body) but a different pronunciation, By analogy, enemies in auditory word perception can be defined as words with the same phonological rime but a different spelling. 
APPENDIX

Item Means, Familiarity Ratings,

Word Structure, and Phonetic Structure

\begin{tabular}{|c|c|c|c|c|c|}
\hline Word & $\mathrm{RT}$ (msec) & Err (\%) & Fam & WS & PS \\
\hline \multicolumn{6}{|c|}{ Consistent words } \\
\hline bague & 774 & 9.1 & 5.98 & $\mathrm{CVC}$ & BVB \\
\hline biche & 733 & 4.5 & 4.35 & CVC & BVS \\
\hline bribe & 741 & 13.6 & 2.96 & CCVC & BLVB \\
\hline broche & 881 & 9.1 & 4.46 & CCVC & BLVS \\
\hline bronze & 860 & 9.1 & 4.62 & $\mathrm{CCVC}$ & BLVZ \\
\hline chauve & 834 & 0.0 & 5.18 & $\mathrm{CVC}$ & SVZ \\
\hline clown & 739 & 9.1 & 5.05 & CCVC & PLVN \\
\hline club & 839 & 0.0 & 5.26 & $\mathrm{CCVC}$ & PLVB \\
\hline code & 793 & 4.5 & 5.18 & $\mathrm{CVC}$ & PVB \\
\hline combe & 862 & 31.8 & 1.68 & $\mathrm{CVC}$ & PVB \\
\hline crabe & 745 & 4.5 & 4.83 & $\mathrm{CCVC}$ & PLVB \\
\hline cube & 669 & 4.5 & 5.25 & $\mathrm{CVC}$ & PVB \\
\hline digue & 810 & 0.0 & 3.60 & $\mathrm{CVC}$ & BVB \\
\hline dinde & 632 & 0.0 & 4.61 & $\mathrm{CVC}$ & BVB \\
\hline douche & 774 & 4.5 & 6.76 & $\mathrm{CVC}$ & BVS \\
\hline dune & 668 & 0.0 & 4.4 & $\mathrm{CVC}$ & $\mathrm{BVN}$ \\
\hline gaffe & 766 & 0.0 & 5.95 & $\mathrm{CVC}$ & BVS \\
\hline golf & 612 & 4.5 & 4.23 & CVCC & BVLS \\
\hline grade & 745 & 0.0 & 3.53 & $\mathrm{CCVC}$ & BLVB \\
\hline hache & 799 & 18.2 & 3.98 & CVC & PVS \\
\hline loge & 831 & 13.6 & 3.86 & $\mathrm{CVC}$ & LVZ \\
\hline luge & 831 & 13.6 & 4.18 & $\mathrm{CVC}$ & LVZ \\
\hline moite & 832 & 9.1 & 4.25 & $\mathrm{CVC}$ & NVP \\
\hline nouille & 877 & 4.5 & 6.03 & CVY & NVY \\
\hline pince & 777 & 0.0 & 4.91 & $\mathrm{CVC}$ & PVS \\
\hline pion & 811 & 9.1 & 4.56 & CYV & PYV \\
\hline ruche & 668 & 18.2 & 4.43 & $\mathrm{CVC}$ & LVS \\
\hline slave & 716 & 13.6 & 2.98 & CCVC & SLVZ \\
\hline sonde & 737 & 4.5 & 3.13 & $\mathrm{CVC}$ & SVB \\
\hline stage & 637 & 9.1 & 6.00 & $\mathrm{CCVC}$ & SPVZ \\
\hline tact & 749 & 22.7 & 4.61 & $\mathrm{CVCC}$ & PVPP \\
\hline tige & 690 & 0.0 & 4.51 & $\mathrm{CVC}$ & PVZ \\
\hline tonne & 740 & 9.1 & 4.66 & $\mathrm{CVC}$ & PVN \\
\hline trompe & 719 & 0.0 & 3.33 & $\mathrm{CCVC}$ & PLVP \\
\hline tuile & 787 & 4.5 & 3.9 & CYVC & PYVL \\
\hline
\end{tabular}

Inconsistent words

$\begin{array}{llrrcc}\text { bail } & 844 & 9.1 & 3.75 & \text { CVY } & \text { BVY } \\ \text { beurre } & 853 & 18.2 & 6.53 & \text { CVC } & \text { BVL } \\ \text { bled } & 934 & 9.1 & 4.98 & \text { CCVC } & \text { BLVB } \\ \text { chèque } & 929 & 31.8 & 6.18 & \text { CVC } & \text { SVP } \\ \text { clan } & 915 & 31.8 & 3.95 & \text { CCV } & \text { PLV } \\ \text { daim } & 759 & 13.6 & 4.05 & \text { CV } & \text { BV } \\ \text { dette } & 928 & 13.6 & 4.85 & \text { CVC } & \text { BVP } \\ \text { flair } & 706 & 4.5 & 4.30 & \text { CCVC } & \text { SLVL } \\ \text { flore } & 791 & 18.2 & 4.15 & \text { CCVC } & \text { SLVL } \\ \text { flux } & 725 & 27.3 & 3.25 & \text { CCV } & \text { SLV } \\ \text { frein } & 802 & 4.5 & 5.86 & \text { CCV } & \text { SLV } \\ \text { gamme } & 815 & 9.1 & 3.78 & \text { CVC } & \text { BVN } \\ \text { gond } & 820 & 27.3 & 2.15 & \text { CV } & \text { BV } \\ \text { gourd } & 837 & 50.0 & 1.61 & \text { CVC } & \text { BVL } \\ \text { greffe } & 802 & 9.1 & 3.70 & \text { CCVC } & \text { BLVS } \\ \text { grêle } & 837 & 13.6 & 4.31 & \text { CCVC } & \text { BLBL } \\ \text { grès } & 795 & 36.4 & 2.14 & \text { CCV } & \text { BLV } \\ \text { grippe } & 867 & 9.1 & 5.75 & \text { CCVC } & \text { BLVP } \\ \text { grog } & 764 & 13.6 & 3.23 & \text { CCVC } & \text { BLVB } \\ \text { grue } & 739 & 18.2 & 3.81 & \text { CCV } & \text { BLV }\end{array}$


APPENDIX (Continued)

\begin{tabular}{lcrrrr}
\hline Word & RT $(\mathrm{msec})$ & Err $(\%)$ & Fam & WS & PS \\
\hline hall & 845 & 45.5 & 4.93 & CVC & PVL \\
jeun & 784 & 42.8 & 4.60 & CV & ZV \\
lard & 804 & 9.1 & 4.18 & CVC & LVL \\
noce & 831 & 18.2 & 3.83 & CVC & NVS \\
paon & 761 & 45.5 & 3.23 & CV & PV \\
plomb & 816 & 22.7 & 4.38 & CCV & PLV \\
pull & 859 & 31.8 & 6.75 & CVC & PVL \\
sauce & 711 & 4.5 & 5.98 & CVC & SVS \\
snob & 755 & 4.5 & 4.63 & CCVC & SNVB \\
sphère & 881 & 31.8 & 3.51 & CCVC & SSVL \\
tiers & 908 & 36.4 & 4.06 & CYVC & PYVL \\
transe & 760 & 13.6 & 4.01 & CCVC & PLVS \\
truie & 765 & 18.2 & 3.20 & CCYV & PLYV \\
vrac & 830 & 9.1 & 4.73 & CCVC & ZLVS \\
yacht & 697 & 27.3 & 3.78 & YVC & YVP \\
\hline
\end{tabular}

Note-RT, reaction times; Err, percentage of errors; Fam, rated familiarity $(1=$ very unfamiliar, $7=$ very familiar $)$; WS, word structure $(\mathrm{C}$, consonant; $\mathrm{V}$, vowel); PS, phonetic structure $(\mathrm{Z}$, consonant fricative voiced; $S$, consonant fricative unvoiced, $N$, nasal, L, liquid, B, stop voiced, P, stop unvoiced, Y, semivowel).

(Manuscript received August 18, 1997;

revision accepted for publication February 3, 1998.) 